\title{
Las tensiones entre lo individual y lo social: Un diálogo interdisciplinario entre la teoría social y los estudios del discurso
}

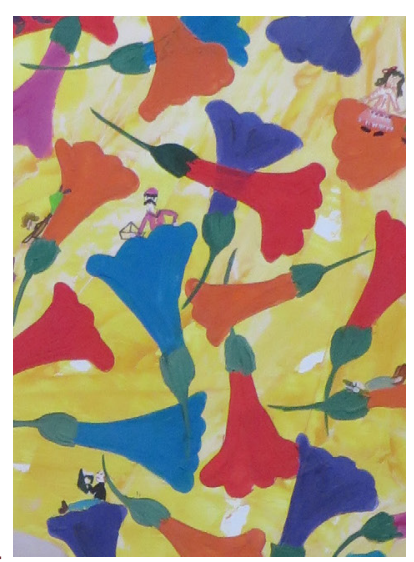

\author{
Paula Salerno \\ Centro de Estudios del Lenguaje en Sociedad (CELES) de la Universidad Nacional \\ de San Martín / CONICET, Argentina \\ psalerno@unsam.edu.ar

\begin{abstract}
Hernán Caneva
Centro Interdisciplinario de Metodología de las Ciencias Sociales (CIMeCS) Instituto de Investigaciones en Humanidades y Ciencias Sociales (IdICHS) de la Universidad Nacional de La Plata, Argentina hernancaneva@gmail.com
\end{abstract}

Trabajo recibido el 30 de abril de 2021 y aprobado el 2 de agosto de 2021.

\begin{abstract}
Resumen
Este artículo propone un diálogo interdisciplinar entre la sociología y la lingüística, para abordar algunos problemas teórico-metodológicos implicados en la tensión entre lo individual y lo social. En esta dirección, y con vistas a analizar problemáticas sociales de la Argentina, avanzamos en una propuesta que ensaya puentes entre el análisis del discurso y la teoría sociológica contemporánea. Para ello, desarrollamos una mirada crítica sobre nuestras disciplinas que apunta a destacar el carácter interpretativo y situado de la práctica de la investigación social, profundizando en una revisión sobre los alcances y limitaciones del análisis del discurso en su aproximación a las "experiencias" de agentes sociales, y articulando esta revisión con los aportes de la corriente sociológica microinteraccionista. La revisión de estos dos campos teóricos nos permite avanzar en una propuesta metodológica que enfatiza la pertinencia de analizar de forma combinada los aspectos micro de las interacciones cara a cara y los aspectos estructurales que las atraviesan. Para sellar este desafío heurístico, proponemos ejemplos recuperados de nuestras propias investigaciones.
\end{abstract}

Palabras clave: dịscurso, tensión individuo-sociedad, estudios del discurso, sociología, microinteraccionismo. 


\title{
Tensions between the individual and the social: An interdisciplinary dialogue between Social Theory and Discourse Studies
}

\begin{abstract}
With the goal of addressing certain theoretical and methodological problems related to the tension between the social and the individual dimensions of our research, in this paper we establish an interdisciplinary dialogue between Sociology and Linguistics. By doing so, our objective is to build bridges between Discourse Analysis and Contemporary Sociological Theory. Thus, in order to underline the interpretative and situated features of the practice of social research, we carry on a critical perspective into our disciplines. On the one hand, we expose a critical revision of the scope and limitations of discourse analysis concerning social agents' experiences. On the other hand, we link that revision to the contributions of the sociological approach known as micro-interactionism. The overhaul on these two theoretical fields will let us outline a methodological proposal which emphasizes how relevant it is to analyse the micro elements of face to face interactions and the structural dimension that influences them, in an articulated approach. We settle this heuristical challenge by providing two analytical examples from our own research.
\end{abstract}

Keywords: discourse, tension between individual-society, discourse studies, sociology, micro-interactionism.

\section{As tensões entre o individual e o social: Uma conversa interdisciplinar entre a teoria social e os estudos do discurso}

\section{Resumo}

Neste trabalho, propomos um diálogo interdisciplinar entre sociologia e linguística, para abordar alguns problemas teórico-metodológicos envolvidos na tensão entre o individual e o social. Nesse sentido, e a fim de analisar as problemáticas sociais da Argentina, fazemos uma proposta para construir pontes entre a análise do discurso e a teoria sociológica contemporânea. Para isso, desenvolvemos uma aproximação crítica sobre as nossas disciplinas que aponta para destacar o carácter interpretativo e situado da prática da pesquisa social, aprofundando numa revisão sobre os alcances e as limitações do análise do discurso na sua aproximação às "experiências" dos agentes sociales, e articulando esta revisão com as contribuições da perspectiva sociológica micro-interacionista. A revisão destes dois campos teóricos permite-nos avançar numa proposta metodológica que salienta a pertinência de analisar combinadamente os aspectos micro das interações frente a frente e os aspectos estruturais que as percorrem. Para fechar este desafio heurístico, propomos dois exemplos extraídos das nossas próprias investigações.

Palavras-chave: discurso, tensão indivíduo-sociedade, estudos do discurso, sociologia, micro-interacionismo. 


\section{Introducción}

El presente trabajo surge de una serie de preguntas teórico-metodológicas acerca de los alcances de las investigaciones que se desarrollan actualmente en el campo de las ciencias humanas y sociales y, sobre todo, las investigaciones centradas en discursos. Específicamente, la preocupación que guía nuestra reflexión es cómo articular las tensiones entre el individuo y la sociedad a la hora de llevar adelante estudios enfocados en el lenguaje en uso, particularmente sobre discursos producidos en la Argentina contemporánea. Si la interdisciplinariedad es recurrente en estos campos de estudio, donde ya se han iniciado investigaciones preocupadas por la articulación entre los estudios del discurso y otras disciplinas que investigan diversas problemáticas sociales (Salgado Andrade 2019), la pregunta es cómo realizar un abordaje cuya interdisciplinariedad sea susceptible de recuperar y problematizar relaciones de distinta índole entre las dimensiones particulares y las estructuras que hacen a los fenómenos que estudiamos. Partiendo de la convicción de que tal abordaje requiere una reflexión crítica sobre los propios campos del saber, en este artículo proponemos un diálogo entre nuestras disciplinas de formación, la sociología y la lingüística, atendiendo respectivamente a la teoría sociológica contemporánea y a los estudios del discurso.

La multidimensionalidad y complejidad que revisten los fenómenos sociales que atraviesan nuestro tiempo exigen particulares esfuerzos epistemológicos, teóricos y metodológicos. Estos esfuerzos han ocupado a la teoría sociológica contemporánea desde mediados del siglo XX hasta el presente, a partir de sistemáticos compromisos intelectuales por elaborar cuerpos de teoría unificados que revelaran los problemas de la conformación del orden social, así como el papel de la acción individual y colectiva en su producción y reproducción (Alexander 2000; Collins 1996; Giddens y Turner 1990). Por su parte, desde la década de 1960 los estudios del discurso se han preocupado por las relaciones entre el lenguaje, la ideología y el poder, apostando cada vez más por un enfoque multidisciplinario en sus distintas escuelas del análisis del discurso (Foucault 1970; Pêcheux 1984; Fairclough 2003, 2013; Wodak y Meyer 2001; Wodak 1996), pero también en la sociolingüística (Labov 1972) y el análisis de la conversación (Tusón Valls 1997; Atkinson y Heritage 1984; Lerner 2004), entre otras.

En cada área disciplinar, las tensiones entre las dimensiones individual y social se manifiestan de distintas formas y plantean variados interrogantes. Entre ellos, ¿las instituciones, los rituales y las normas que atraviesan el proceso de socialización deben estudiarse aisladamente de la acción en su carácter práctico y voluntarista?, ¿cuál es o debería ser la relación entre el enfoque microsociológico sobre las interacciones y el enfoque sobre dimensiones estructurantes de la vida en sociedad? En cuanto al análisis del discurso, ¿cómo se relacionan los discursos dominantes con los discursos alternativos o provenientes de lugares marginales de la sociedad?, ¿el análisis de discursos pronunciados por líderes de la política permite comprender fenómenos sociales de una manera significativa o es necesario considerar también otros tipos discursos? 
En suma, ¿cómo pensar perspectivas o programas de investigación que, a través de la interdisciplinariedad teórica y metodológica, nos permitan analizar conjuntamente los conflictos entre las determinaciones de las estructuras sociales, económicas y políticas y la agencia individual y colectiva que las reproduce, pero también las desafía y las transforma?

A continuación, realizaremos una revisión de las problemáticas que han presentado algunos abordajes del análisis del discurso, especialmente aquellos que adoptan una mirada determinista que dificulta la consideración de las relaciones entre individuo y sociedad. Luego, a la luz de estas problemáticas, expondremos cómo ha sido trabajada la relación individuo-sociedad en la teoría sociológica contemporánea. Esto dará lugar a nuestra propuesta metodológica, basada en la articulación entre aportes de una perspectiva discursiva de la desigualdad lingüística y un enfoque microsociológico de las experiencias y discursos. Finalmente, para plantear cómo estos diálogos entre disciplinas encuentran terrenos fértiles en los análisis empíricos, proporcionaremos dos ejemplos de nuestras investigaciones: en un caso, sobre los discursos acerca de la guerra de Malvinas; en el otro, sobre el problema de la despenalización y legalización del aborto en Argentina.

\section{Análisis del discurso: una revisión crítica}

Por demás conocidas son las fortalezas del análisis del discurso a la hora de trabajar con materiales tanto verbales como no verbales en investigaciones preocupadas por las relaciones entre el lenguaje y distintos fenómenos sociales. Particularmente, consideramos el análisis del discurso como práctica interpretativa y como campo interdisciplinario (Zima 2005; Arnoux 2006, 2019), que se preocupa por las relaciones que el discurso establece con la historia, la ideología y lo político. Desde esta mirada, el discurso es una práctica social y, según Fairclough $(1992,2003)$, una parte constitutiva de la vida social, con la cual establece una relación dialéctica. Esta posición se inspira en Foucault (1970), quien considera que en el discurso y por él se producen y reproducen relaciones de poder. En esta línea, Fairclough (2003) define las ideologías como representaciones del mundo social que permiten establecer, mantener y modificar las relaciones sociales de poder, dominación y explotación. Por eso, explica, el análisis debe enfocarse en los efectos ideológicos de los discursos, y hacerlo mediante una articulación entre las dimensiones textual y social que trascienda las divisiones disciplinares. Así, este autor entiende el análisis del discurso como una perspectiva que oscila entre el abordaje de textos específicos y la relativamente duradera estructuración social del lenguaje, a la que denomina "orden del discurso". En relación con esto, uno de los aportes principales del análisis del discurso es la postulación de Pêcheux (1975) sobre el carácter "ilusorio" de la agentividad del sujeto hablante. Según el académico francés, el sujeto no es voluntario de su decir, sino que está atravesado por el discurso, que es eminentemente ideológico. Desde la postura de Fairclough y Wodak, además, podemos decir que el sujeto es constituido por el discurso, en tanto este último "constituye lo social" (2000:367). 
Desde el punto de vista metodológico, el análisis del discurso aporta herramientas exhaustivas para abordar la materialidad lingüística desde una perspectiva interdisciplinaria que requiere, por un lado, un ir y venir constante de los datos al contexto de producción del discurso analizado y, por otro lado, el diálogo con distintas disciplinas, a las que se recurre de acuerdo a las características de cada investigación. Como explica Arnoux (2006), debido a las relaciones ya mencionadas entre lo discursivo y lo social, el análisis puede necesitar los aportes de las ciencias sociales, que permitan explicar las prácticas sociales. Esta dimensión de la interdisciplinariedad remite, por su parte, a la definición de discurso como "articulación de un texto y un lugar social" (Maingueneau 1999, 65). A la vez, explica la autora, los discursos son abordados por las ciencias humanas, sociales, e incluso médicas, que se valen del análisis del discurso como caja de herramientas para investigar problemáticas específicas de cada campo. Un último aspecto de la interdisciplinariedad de esta corriente radica en su interrelación con las diferentes disciplinas de las ciencias del lenguaje, a las que también se recurre para analizar la materialidad lingüística según los enfoques y objetivos del análisis. Este punto trae a colación un aspecto metodológico central: desde esta perspectiva, las categorías de análisis no están dadas de antemano, sino que se construyen según los problemas que van apareciendo en el análisis y los materiales con que se trabaja, siguiendo procedimientos exploratorios que requieren una constante revisión de las hipótesis de investigación.

Entendiendo que el lenguaje en uso puede ser estudiado de manera profunda desde una perspectiva discursiva, queremos presentar en este apartado algunos reparos sobre determinadas formas en que suele ser implementado el análisis del discurso en investigaciones que adoptan enfoques deterministas. Aportaremos, sobre todo, una revisión crítica de las debilidades que hemos encontrado en nuestras propias investigaciones doctorales y que se vinculan en buena parte con problemáticas habituales en la práctica analítica de este campo ${ }^{1}$.

En primer lugar, los abordajes como el señalado suelen desestimar la capacidad de agencia del sujeto hablante. Desde el análisis crítico del discurso, Flax (2021) alerta sobre el "riesgo de paternalismo" que acarrea el postulado de la no voluntad del sujeto, el cual implica que las investigaciones en el "análisis del discurso mainstream" ${ }^{2}$ buscan develar los mecanismos mediante los cuales las personas son manipuladas por el discurso. Esto ha sido señalado por Bonnin (2019a), para quien la falta de atención a las personas que producen textos específicos y participan de prácticas sociales encarna una contradicción: se analizan los discursos y estilos en relación con las personas que los hacen posibles, pero borrando o mitigando la

1 Para una síntesis completa de los principales cuestionamientos al análisis crítico del discurso, ver Bonnin (2019a).

2 Esta expresión es de Blommaert (2005), quien usa el término “mainstream" para referirse al análisis crítico del discurso representado principalmente por Wodak (1995) y Fairclough (1992), que, según el autor, se centra únicamente en reaccionar en contra del poder. En debate con la habitual asociación entre adoptar un "enfoque crítico" y adoptar un "enfoque que critica el poder", Blommaert propone analizar las condiciones y los efectos del poder, el principal de los cuales es la desigualdad. Especialmente, sostiene que es fundamental estudiar cuál es y cómo es el impacto del poder en las personas, grupos y sociedades. 
capacidad de agencia de tales personas. Desde nuestra mirada, esto da cuenta de que los aspectos estructurales ocupan el centro de la escena, en detrimento de la dimensión individual de las cuestiones sociales abordadas en el análisis. En la misma línea, el autor señala que, si bien el análisis del discurso en su vertiente francófona estudia situaciones de enunciación a partir de la identificación de huellas de la subjetividad en el lenguaje, en ocasiones la escena de enunciación es observable solo de forma indirecta, a través de una serie de reglas que definen tipos de textos, y no a través de textos y situaciones concretas. En suma, para Bonnin, el lugar secundario y excepcional que ocupa la singularidad en este tipo de análisis lleva a una generalización que impide comprender los datos en sus contextos específicos. A esto debemos agregar que la desestimación de la agencia subjetiva y el consecuente sobredimensionamiento del rol de le analista pueden llevar a nublar los límites entre la interpretación del discurso analizado y el conocimiento sobre las condiciones específicas en que ese discurso se ha producido. En última instancia, se pierde de vista que también le analista, en tanto sujeto hablante, produce conocimientos desde una posición definida cultural y personalmente.

Una segunda cuestión a problematizar en el análisis del discurso es la prioridad que se le suele dar a corpora homogéneos y predominantemente compuestos por textos escritos. Incluso si se busca comprender discursos originalmente orales, como por ejemplo aquellos s pronunciados desde un atril por personalidades políticas, las investigaciones suelen conformar corpora de transcripciones y desatender los aspectos proxémicos, gestuales y audiovisuales en general, tal como ocurre en Salerno (2019). En su revisión de la noción de "voz", Bonnin (2019b) critica el "tratamiento monológico" de los datos, tan habitual entre las investigaciones realizadas desde los estudios del discurso. Los análisis, explica, tienden a priorizar las representaciones discursivas de interacciones y a dejar en segundo plano las interacciones reales entre personas concretas (Bonnin 2019a, 2019b; Bolívar 2018, 2010). Nuevamente, se desestima la individualidad de ese discurso, determinado en gran medida por la persona que lo produce y la situación de enunciación específica. Una crítica similar es realizada por Baxter (2003) a la perspectiva feminista del análisis crítico del discurso que más tarde se dio en llamar Análisis Crítico Feminista del Discurso (Lazar 2005)—. Desde un enfoque postestructuralista y feminista, Baxter señala que el ACD desatiende las interacciones comunicativas concretas en las que las posiciones de les hablantes en tanto que poderosas o débiles varían constantemente en distintos contextos discursivos (Baxter 2003, 46). Como contrapartida, la autora propone realizar análisis del discurso mediante técnicas etnográficas para estudiar discursos orales y analizar las tensiones, contradicciones y ambigüedades inherentes a todo texto (Baxter 2003, 2). Desde nuestra lectura, la sobrevaloración de los discursos dominantes en la constitución de corpora, si bien hace posible la generalización de patrones recurrentes en distintos discursos, también conduce a perder de vista un aspecto importante de las problemáticas sociales abordadas, dado por las dimensiones local, cultural o personal que —según el caso- forman parte de tales problemáticas. Por otro lado, la homogeneización de los materiales de análisis y la prioridad de los discursos dominantes también conllevan 
limitaciones para el estudio de problemáticas identitarias, por dos razones. Primero, al desatender las interacciones entre personas y entre discursos, se tiende a reproducir la idea de que el poder se ubica en lugares fijos, que trascienden los discursos particulares y las posiciones que allí se construyen. Es decir, se cae en una contradicción al concebir de manera estática un fenómeno que es dinámico y que hace a los procesos de identificación. Segundo, retomando los planteos de la lingüística sociocultural, el rasgo móvil y cambiante de las identidades está dado en buena parte por el hecho de que estas son relacionales e intersubjetivas (Bucholtz y Hall 2005) y, según Goffman (1997), se construyen en la interacción ${ }^{3}$. Desatender esto conduce a una comprensión parcial del problema de investigación.

Una última tensión que queremos subrayar sobre algunas corrientes deterministas del análisis del discurso es la escasa problematización de las herramientas metodológicas (Martin 2004, Martínez Romagosa y Flax 2020) y, sobre todo, la falta de flexibilidad metodológica que, siguiendo a Bonnin (2019a), resulta de universalizar nociones fundamentales como "texto", "poder" e "ideología". El tratamiento aislado y estático de estas nociones ignora las especificidades de sus sentidos en investigaciones particulares que tienen conjuntos de datos y coyunturas históricas y culturales propias. Esto da cuenta, a la vez, de la "falta de interés en la cultura", que es vista únicamente como un "sistema estático de representaciones y creencias que se distribuyen de forma homogénea entre sus miembros" (Bonnin 2019a, 14). En una mirada similar, Blommaert (2005) realiza dos cuestionamientos: por un lado, el foco en discursos producidos en sociedades específicas, generalmente postindustriales del Primer Mundo, y, por otro, la aplicación acrítica de la lingüística sistémico funcional que lleva a analizar diferentes lenguas según los parámetros gramaticales del inglés. En consecuencia, el análisis del discurso se torna una práctica colonialista en tanto excluye visiones alternativas al mundo occidental ${ }^{4}$. La crítica al enfoque colonialista se plasma con énfasis en la propuesta de los estudios culturales del discurso, orientados a "descolonizar" los discursos y a desarrollar enfoques sobre la comunicación humana que sean culturalmente conscientes, situados localmente y con una visión global (Shi-Xu 2015). Desde la lingüística crítica, Raiter (2014) subraya que en el análisis crítico del discurso es frecuente encontrar interpretaciones incompletas e incluso sesgadas. Según el autor, esto se debe no al desinterés por la cultura sino a la atención privilegiada sobre contextos particulares o usos específicos del lenguaje, y la consecuente falta de atención al lenguaje en uso. En sus palabras, "el análisis [...] decae al confundir funciones del lenguaje con el lugar concreto que algunas interacciones lingüísticas tienen dentro de una comunidad" (Raiter 2014,

3 Desde el análisis del discurso, Amossy (2018) articula la perspectiva de Goffman y la noción retórica de ethos para trabajar "la presentación de sí" y trabajar las problemáticas identitarias de manera fructífera con un enfoque discursivo.

4 Esto se ve especialmente en la llamada "ideología del acceso" que, según Unamuno y Bonnin (2018), es solidaria de un discurso universalista. Este, incluso si considera culturas particulares, lo hace en base a dos principios de corte etnocentrista: 1) las identidades son subordinadas a políticas universalistas occidentales definidas por el estado-nación, y orientadas a la inclusión más que a la valorización de las poblaciones minorizadas y sus lenguas; 2 ) el lenguaje es entendido como un código transparente, lo cual manifiesta una mirada reductivista y conservadora sobre la interculturalidad, entendida simplificadamente como un intercambio de información. En esto consiste la mirada monoglósica del lenguaje y la cultura, que en última instancia afianza las relaciones de dominación del mundo occidental sobre otras poblaciones. 
22). Para Flax (2021), en cambio, quien se inspira en Blommaert (2005), la causa de esta mirada parcial es la falta de una teoría social que permita explicar las interpretaciones realizadas sobre la materialidad lingüística considerando factores sociales, económicos e históricos, entre otros.

La falta de agentividad del sujeto, la homogeneidad de los corpora que tiende a privilegiar discursos dominantes y la universalidad de los conceptos teóricos son las tres cuestiones principales que guían nuestras reflexiones y orientan nuestra propuesta metodológica, en la cual la interdisciplinariedad es central.

\section{La relación individuo-sociedad desde la teoría sociológica contemporánea}

Uno de los propósitos centrales de la sociología como disciplina científica consiste en conocer las reglas, pautas, normas y estructuras que organizan a las sociedades contemporáneas, problematizando el lugar de los individuos y grupos como agentes de su reproducción y transformación. Este propósito -aunque casi evidente para quienes conforman el campo- supone un conjunto de discusiones epistemológicas, teóricas y metodológicas. Pues, ¿cómo abordar analíticamente esta relación?, ¿qué ideas, categorías, conceptos, metodologías y métodos son los más adecuados?

En efecto, tanto la teoría sociológica decimonónica como la que se gestó durante los años 30 del siglo XX en Europa y Estados Unidos, y que bien podemos llamar "teoría social contemporánea", pusieron el foco en el estudio sistemático de la relación/tensión entre el individuo y la sociedad. Esto dio lugar a extendidas discusiones entre "tradiciones" de pensamiento (Collins 1996), las cuales propiciaron enfoques y teorías generales y especiales sobre la sociedad, que sobreviven hasta nuestros días.

Desde mediados del siglo XX, diferentes referentes del campo se propusieron elaborar teorías sistemáticas sobre el funcionamiento de la sociedad, las cuales retoman críticamente las ideas legadas por "los clásicos" de la disciplina (Karl Marx, Max Weber y Émile Durkheim) para desarrollar en forma multidimensional y compleja las relaciones/tensiones entre el individuo y la sociedad. El debate sociológico del siglo pasado estuvo atravesado por el cruce entre perspectivas que se centraron o bien en el carácter "racional" de la acción o bien en el carácter "no racional" o "normativo". Por otra parte, el debate estuvo signado por perspectivas enfocadas ya en una mirada "holística" del orden social, ya en una mirada "individualista". Asimismo, las corrientes de pensamiento se diferenciaron en su concepción acerca del carácter funcional/ armónico del orden o, por el contrario, sobre su carácter conflictivo.

De las diferentes tradiciones de pensamiento, y dada su estrecha relación con los problemas que atañen al orden de lo simbólico, al lenguaje y a los estudios del discurso, nos interesa pasar breve revista de la sociología durkheimiana y detenernos en una de sus derivas contemporáneas: la sociología "microinteraccionista" de Erving Goffman. 
La tradición de pensamiento encabezada por Émile Durkheim (1982) plantea una perspectiva holística sobre el orden social, centrada en los elementos simbólicos que garantizan la cohesión e integración entre sus miembros o partes. Su propuesta se basa principalmente en analizar los mecanismos que permiten el equilibrio entre los diferentes sistemas, grupos, asociaciones e individuos (rituales, símbolos, creencias, valores, reglas, normas, instituciones, etc.).

Este sociólogo "clásico" concebía a la acción humana en sociedad no tanto como una acción "instrumental" orientada por los condicionamientos externos del medio ni en conflicto con ellos, sino más bien como una acción "no racional" orientada por elementos "internos" que provenían del individuo y que dependían, en buena medida, de su proceso de socialización. A partir de estas ideas, la obra de Durkheim abrió un interesante terreno de exploración acerca de la subjetividad humana, poniendo particular énfasis en los componentes simbólicos y en los aspectos normativos y morales que orientan los comportamientos de los individuos.

Una de las perspectivas influidas por su teoría, aunque con radicales diferencias en la consideración de la preeminencia de las estructuras por sobre los individuos, es la sociología de Goffman (1991, 1997, 2019). En línea con Joseph (1999), se puede sostener que Goffman tomó distancia del estructural-funcionalismo, pero también -y en línea con el sociólogo francés Pierre Bourdieu - se alejó de la concepción de un individuo abstraído de las estructuras, para poner el acento en el estudio de la "experiencia individual" que supone vivir en sociedad.

La corriente denominada "microsociología", de la que Goffman fue fundador, propone analizar la interacción social en sus unidades mínimas, esto es, analizar cómo se produce el encuentro entre dos o más individuos. Según este autor, analizar el comportamiento de grupos pequeños es una vía teórica y metodológica para comprender cómo se produce-reproduce la sociedad. En su trabajo La presentación de la persona en la vida cotidiana, el autor elabora un marco conceptual que le permite estudiar el modo en que la vida social se produce en establecimientos, a los que define como "todo lugar rodeado de barreras establecidas para la percepción, en el cual se desarrolla de modo regular un tipo determinado de actividad" (Goffman 1997, 254).

Goffman dedicó buena parte de su obra a desarrollar un esquema conceptual para analizar cómo se producen las interacciones sociales (cómo se inician y cómo se sostienen), así como las actuaciones de los individuos involucrados y los aspectos o características de los escenarios en que se desarrollan. Aquí nos interesa preguntarnos, en línea con Goffman, de qué modo las interacciones están atravesadas por pautas o criterios de acción preestablecidos, así como por roles sociales diferenciados, los cuales implican derechos y obligaciones específicas. Este interrogante nos desafía particularmente, ya que la perspectiva de Goffman no se agota en describir y analizar la dinámica de las interacciones a nivel micro o "cara a cara", sino que problematiza cuestiones estructurales relacionadas con el lenguaje, 
la comunicación y la cultura. Es decir, una microsociología debe aportar datos para comprender los aspectos materiales y simbólicos que atraviesan y condicionan el desarrollo de las interacciones cara a cara, pero también, pensamos aquí, de las interacciones entre discursos que se dan de formas más o menos evidentes. Estos condicionamientos son de diversa índole, pero en general están asociados a los criterios morales que organizan la vida social y su relación con pautas de acción institucionalizadas. De allí, la influencia de la teoría durkheimiana.

Entonces, un tema crucial para comprender la relación entre individuo y sociedad según este enfoque estriba en conceptualizar las interacciones sociales como encuentros donde les agentes "actuamos". Siguiendo este argumento, Goffman concibe la vida social como una "dramaturgia" en la que les agentes actúan según guiones más o menos preestablecidos, obedeciendo pautas de acción y expectativas de situación con las que están más o menos de acuerdo. Esto lo lleva a prestar atención particularmente a los elementos no verbales (la gestualidad y las expresiones, principalmente) presentes en el encuentro entre dos o más individuos. Entonces, su sociología propone desentrañar el modo como los individuos se expresan en las interacciones, poniendo el foco en la observación de las impresiones que dan y que emanan de ellos.

Debemos considerar que para que una interacción se realice "exitosamente" es preciso que las personas involucradas formulen una "definición de la situación" que las involucra, la cual debe coincidir —como mínimo- en aspectos prácticos elementales. Debe producirse lo que Goffman denomina "consenso de trabajo", es decir, una suerte de acuerdo que implica que los individuos sean capaces de discernir qué es lo que resulta más "apropiado" para que un encuentro se realice exitosamente. Por esta razón, cabe señalar — con Goffman- que los encuentros no ocurren en el vacío, ya que incluso aunque los individuos involucrados no se conozcan entre sí, existe cierto acervo cultural que permite dominar las habilidades necesarias para que la interacción prospere. Es una suerte de "compromiso moral" el que, en definitiva, permite garantizar la supervivencia de la situación en la que cada individuo se involucra. Ahora bien, ¿cómo y por qué se (re)produce este "compromiso moral" entre los individuos?

Goffman propone analizar las "rutinas" o "papeles", es decir, las pautas de acción preestablecidas que los individuos reproducen en múltiples situaciones de su vida cotidiana. Estas "rutinas" son producidas y reproducidas a partir de diferentes dispositivos que se fijan en las instituciones, en los discursos, en los cuerpos y en todo un conjunto de rituales sociales. Una de las derivaciones metodológicas de la perspectiva goffmaniana nos conduce a observar los encuentros "cara a cara", a través de métodos ligados a la etnografía. La otra, no ajena a la primera, nos lleva a un análisis de los elementos subyacentes del orden de la cultura (sentidos, creencias, normas, rituales, discursos) que se indexan en las interacciones de distinto tipo que ocurren en la vida cotidiana. De ahí, la pertinencia de poner en diálogo un enfoque sociológico que enfatiza la experiencia individual, pero compartida, que supone vivir en sociedad con otro enfoque como el análisis del discurso, 
atento a las relaciones entre lenguaje, ideología y poder. Como ilustraremos en el apartado 4, esta articulación nos lleva a concebir las interacciones en un sentido doble, como diálogo cara a cara entre personas físicamente presentes y como interacción discursiva en el sentido bajtiniano, es decir, considerando la condición dialógica de todo enunciado.

Particularmente, un campo de problemas que Goffman aborda radica en el análisis de discursos que escenifican prácticas, interacciones, rituales y estereotipos relacionados a los géneros sociales masculino y femenino. En su trabajo La ritualización de la feminidad (1991), el autor confecciona una colección de fotografías publicitarias de diarios y revistas en las que se escenifican interacciones entre varones y mujeres. A partir del estudio de imágenes fijas, descubre ciertas recurrencias referidas a los "estilos de comportamiento" (actitudes, gestos, posturas) que son imputados a cada persona según su género social, desde una mirada binaria. Su propósito es desenmascarar a través de una labor interpretativa y reflexiva lo que está dado o "a simple vista".

Según Goffman (1991), las imágenes publicitarias analizadas describen y, asimismo, "refuerzan" un lenguaje ritual que ya forma parte de la cultura. En relación a la problemática de género, se puede sostener que los encuentros o interacciones entre varones y mujeres son montados por la industria cultural para fortalecer el poder prescriptivo de estereotipos y estilos de comportamientos ligados a los sexos masculino y femenino, en el marco de rituales que son más o menos conocidos por las destinatarias (por ejemplo, el ritual del cortejo, la seducción, la actitud "protectora" del varón, la "caballerosidad" al dejar el paso a una mujer, etc.). Lo que hacen las publicidades, a través del dispositivo semiótico de la imagen, es caricaturizar y dramatizar el ritual, llevándolo a un segundo nivel o grado. Para Goffman, la colección de imágenes revela cómo diversos estilos de comportamiento que relacionan a varones y mujeres en el espacio público y privado proyectan rituales ya existentes y al mismo tiempo los exageran. Es decir que las publicidades realizan "hiperritualizaciones" de la realidad social.

Su sociología, entonces, nos invita a observar en detalle las interacciones (actuaciones y encuentros) que se dan entre actores individuales en diferentes ámbitos de la vida cotidiana. Pero también nos permite indagar cómo estas experiencias individuales y sociales están atravesadas por marcos normativos, por reglas morales e institucionales que prefiguran límites y posibilidades para la actuación.

\section{Desafíos de la interdisciplinariedad para pensar fenómenos sociales desde un enfoque discursivo}

\subsection{Nuestra propuesta}

Desde nuestro punto de vista, el análisis del discurso tiene mucho que aportar a las investigaciones preocupadas por las relaciones entre los fenómenos sociales y el lenguaje en uso. Como punto de partida, decidimos 
posicionarnos en el campo más vasto de los estudios del discurso, que entendemos como una gama de disciplinas de las ciencias del lenguaje que estudian las relaciones entre poder y discurso. Esto incluye el análisis del discurso en sus distintos enfoques, pero también la sociolingüística, el análisis de la conversación y el análisis multimodal, entre otras. Retomando las problemáticas planteadas y los aportes de la perspectiva goffmaniana, proponemos que los trabajos desde este campo disciplinario deben apostar por la riqueza de aquellos problemas de investigación que combinan el afán desenmascarador de las miradas estructuralistas y una consideración de la agentividad de los sujetos del discurso. En otras palabras, proponemos dirigir la mirada hacia problemáticas sociales que ponen su foco en las relaciones entre voces sociales y voces individuales, así como entre discursos dominantes y discursos alternativos que puedan dar cuenta de las interacciones entre la individualidad y las estructuras de dominación que guían lo social. En suma, buscamos considerar los vínculos entre distintas formas de concebir las dimensiones social e individual de los discursos.

Nuestra propuesta teórico-metodológica radica en la articulación entre algunos aportes de la perspectiva discursiva de la desigualdad lingüística (Bonnin 2019a) y la perspectiva goffmaniana centrada en la interpretación de la experiencia desde un abordaje microsociológico. Esta mirada interdisciplinaria nos permitirá captar la tensión entre la agencia y la estructura, entre la transformación propiciada desde instancias individuales y colectivas y la conservación del orden social. A esto agregamos la valorización de una posición epistemológica que toma en cuenta la dimensión personal de quien realiza la investigación.

Con respecto a la perspectiva de la desigualdad lingüística, Bonnin (2019a) propone estudiar las regularidades de las prácticas sociales teniendo en cuenta la singularidad de las personas y los eventos en que estas participan. Así, para comprender las tensiones entre singularidad y regularidad, define el discurso como emergente interaccional. Desde esta mirada, el discurso no es ni social ni individual, sino interaccional: se produce en interacciones reales entre hablantes. Por su parte, el carácter emergente del discurso radica en que es un "repertorio en constante desarrollo que solo existe en eventos de interacción concretos" (Bonnin 2019a, 25).

Para evitar el sesgo monológico que tienen algunos abordajes discursivos, Bonnin busca revalidar la noción de "voz individual", entendida como un "conjunto de regularidades semióticas que indexicalizan una biografía" (2019b, 234). Siguiendo esa mirada, subrayamos la riqueza de construir corpora heterogéneos y de considerar relatos de vivencias personales producidos en interacciones concretas, los cuales pueden ser significativos para el análisis de prácticas discursivas que den cuenta de dinámicas de dominación y resistencia. Siguiendo, entonces, la perspectiva discursiva sobre la desigualdad lingüística (Bonnin 2019a), rescatamos la importancia de la noción de voz, desde la posición de Jan Blommaert: 
efectos del poder -(no) ser entendida/o, en términos del conjunto de reglas y normas socioculturales específicas-así como de las condiciones para el poder -lo que cuesta para cada hablante lograr ser entendida/o (Blommaert 2005, 5; traducción nuestra)

Por un lado, el análisis de las voces permite incorporar las interacciones cara a cara en los estudios del discurso preocupados por la desigualdad social. Por otro lado, la indagación sobre las voces sociales nos permite analizar los discursos dominantes y también los que ocupan lugares de subordinación, así como la interacción entre ellos. En este sentido de la interacción discursiva, las voces individuales manifiestan voces socialmente reconocibles, con las que tienden cercanías y distanciamientos.

De la segunda perspectiva teórica que aquí recuperamos nos interesa subrayar la noción de "experiencia". Desde una mirada sociológica centrada en el estudio de las interacciones "cara a cara" como la de Goffman (1997), proponemos que la flexibilidad metodológica surge de considerar los estudios del discurso como caja de herramientas y teorías que permite abordar los acervos culturalmente compartidos de ideas, creencias, condicionamientos y habilidades que intervienen en la reproducción del orden social, así como de las relaciones de poder y dominación que lo atraviesan. El enfoque microsociológico, centrado en la actividad interpretativa de le analista, nos invita a problematizar cómo los discursos, en escenarios situados y mediante diferentes dispositivos semióticos, escenifican interacciones/encuentros que se producen en la vida cotidiana y cómo los imaginarios reproducen posiciones dominantes o subalternas.

En este marco, el trabajo con materiales visuales se torna de particular relevancia. El estudio de las imágenes reproducidas por la industria cultural y publicitaria, como en el caso de Goffman (1991), permite identificar huellas de la "situación" o del contexto en el que se ilustra una interacción. Incluso, el autor explica que su análisis no pretende mostrar cómo funciona la sociedad, sino dar cuenta de cómo las publicidades escenifican rituales que se encuentran ya presentes en la vida social. De esta forma, se pone de manifiesto la dimensión social y estructural de las interacciones cotidianas.

El estudio microsociológico se puede aplicar no solo a documentos como las imágenes publicitarias, sino también al registro de las observaciones participantes y entrevistas en metodologías de corte etnográfico. Este tipo de abordaje posibilita no sólo analizar la dominación hegemónica, sino también las "fracturas" o desacuerdos que subyacen a los presuntos consensos y compromisos normativos que se dan en los encuentros entre distintas personas. Entonces, un análisis interdisciplinar que tenga como norte la práctica interpretativa y reflexiva y que pueda reponer los desacuerdos, disconformidades y "fisuras" subyacentes al orden de "lo hegemónico", debe aportar pistas para problematizar y complejizar los procesos de subjetivación, las identidades/identificaciones sociales y políticas, así como el lugar que en ellas ocupan las experiencias individuales y colectivas.

En cuanto al lugar del sujeto en la investigación, sostenemos que la agentividad de les hablantes debe plasmarse no solo en el enfoque teórico, 
sino también en nuestra metodología: es necesario dislocar el lugar de le investigadore como posición de saber único y objetivo, y apostar por una construcción dialógica del conocimiento. Por eso, no solo adoptamos una "actitud epistemológica hacia la realidad discursiva y las personas que están involucradas en el proceso de investigación" (Bonnin 2019a, 16), sino que entre tales personas incluimos a le investigadore en su dimensión personal, no solo académica. Entonces, por un lado, recuperamos el enfoque semiótico-narrativo de Arfuch (2002), que propone una producción dialógica del sentido y una posición de investigación que considera el carácter "engañoso" de la referencialidad. Para abordar la heterogeneidad de voces es necesario, según la autora, una "ampliación y sensibilización de la escucha" que tenga en cuenta tanto lo dicho como lo no dicho (Arfuch 2002 , 197). Por otro lado, apuntamos a cambiar las prácticas investigativas apostando por un quehacer reflexivo inspirado en la epistemología feminista, que privilegia los conocimientos situados y la responsabilidad social de las ciencias (Haraway 1995).

\subsection{Dos ejemplos}

A continuación, presentamos dos ejemplos tomados de nuestras propias investigaciones. En ambos, tratamos de abordar las relaciones entre lo social y lo individual adoptando una perspectiva discursiva basada en la interacción. En un caso, se propone una mirada dialógica en un intercambio concreto entre hablantes mujeres que participaron en la guerra de Malvinas y se observa el diálogo entre sus propias voces individuales y determinadas voces sociales. En el otro caso, se establece una interacción entre dos discursos que tratan el tema de la despenalización y legalización del aborto desde miradas antagónicas, ilustrando muy diferentes concepciones sobre la experiencia (individual y social) implicada en la práctica de la interrupción voluntaria del embarazo. En ambos casos, trabajamos con discursos que son semióticamente complejos y que están atravesados por dispositivos que determinan su circulación. A los fines de este artículo, consideramos exclusivamente la dimensión verbal en el primer análisis y las dimensiones verbal y visual en el segundo.

\subsubsection{Ejemplo 1}

Veamos un ejemplo tomado de la investigación posdoctoral de Salerno (2021a, b). A continuación, presentamos una entrevista televisiva realizada a mujeres que participaron de la guerra de Malvinas (1982) integrando el bando argentino. La entrevista fue transmitida por el canal de cable Todo Noticias el 2 de abril ${ }^{5}$ de 2015, conducida por el periodista Nelson Castro. Las entrevistadas fueron cinco mujeres: dos que en el momento de la contienda eran enfermeras profesionales de la Fuerza Aérea y tres que eran aspirantes navales a enfermería de la Escuela de Sanidad Naval de la Armada. Mientras las primeras eran mayores de edad en 1982 y después

5 Cada 2 de abril se celebra en Argentina el Día de los Caídos y Veteranos de la Guerra de Malvinas, ocurrida entre el 2 de abril y el 14 de junio de 1982, entre Argentina y Gran Bretaña. Si bien el marco epidíctico signado por la efeméride es importante en la configuración de estos discursos, a fines expositivos no será tenido en cuenta en este trabajo. 
de la guerra han recibido reconocimientos de la Fuerza, las segundas eran menores de edad y en esta entrevista reclaman que la Armada niega que hayan participado en el conflicto. La desigualdad en las realidades de estos dos grupos de mujeres es importante para el desarrollo de la interacción. Mediante el análisis de la entrevista, se puede observar cómo, al narrar sus propias vivencias de la guerra, las diferentes mujeres despliegan mecanismos discursivos de auto-identificación para legitimar sus experiencias y, con ello, sus reclamos.

Presentamos a continuación un fragmento pronunciado por Alicia Reynoso, quien integra el grupo de mujeres de la Fuerza Aérea. A diferencia de otros enunciados similares de estas mismas mujeres en otros medios de comunicación, en los que ellas se auto-identifican como veteranas y se comparan con los veteranos varones, en esta entrevista Alicia y sus compañeras hacen hincapié en su condición de enfermeras profesionales. Esto se observa, por ejemplo, en la respuesta a una pregunta acerca de sus recuerdos sobre el momento de la convocatoria a la guerra:

Periodista: [...] ¿Qué recuerdan del momento en que fueron convocadas?

\begin{abstract}
Alicia Reynoso: Bueno, nosotros, desde el momento en que fuimos convocadas lo que más nos recuerda el alto honor que teníamos de estar pasando por ese momento que desde nuestra profesión como enfermeras estábamos sirviendo a la patria en un momento tan especial. Y realmente nos llenaba de orgullo poder cumplir con lo que habíamos estudiado y, nosotras que éramos enfermeras militares, las primeras en Argentina, poder cumplir el rol para el cual la Fuerza nos había preparado. (TN, 02/04/2015)
\end{abstract}

En este enunciado, que es la primera intervención de Alicia en la entrevista, la evocación de voces sociales específicas se vincula con construcciones identitarias que, a nuestro entender, se plasman en la utilización particular de los géneros gramaticales con que la enunciadora se refiere a sí misma y a sus compañeras. En primer lugar, la auto-designación que combina los géneros gramaticales masculino y femenino ("nosotros [...] fuimos convocadas") se resuelve en un predominio del género femenino ("enfermeras", "las primeras"). La combinación masculino-femenino inicial acompaña el despliegue de un discurso epidíctico, marcado por las expresiones "el alto honor" y "estábamos sirviendo a la patria". Los valores de honor, orgullo y cumplimiento del deber inscriben a la enunciadora en una perspectiva patriótica avalada por una voz social que asociamos al interdiscurso bélico-militar. Cabe señalar que esto es distinto en el caso de las aspirantes navales, que en esta entrevista remiten al discurso patriótico mediante la autodesignación en masculino. En segundo lugar, en el caso citado de Alicia, en cambio, el género femenino brinda singularidad a su propio grupo: lo que la distingue de las aspirantes navales es el carácter inaugural de ser mujer en la Fuerza Aérea, lo cual es otro motivo de orgullo. Así, la autoidentificación de esta hablante se construye a partir de una tensión entre, por un lado, ser una mujer que defiende la legitimidad de su experiencia

6 La entrevista completa se puede ver acá:

https://tn.com.ar/politica/la-conmovedora-historia-de-las-mujeres-invisibles-de-malvinas_580598/. 
en un ámbito tradicionalmente masculino como es el militar —sobre todo, en tiempos de guerra- y, por otro, apelar a la figura de mujer legitimada socialmente, vinculada a las tareas de cuidado. La voz individual sobre la propia experiencia es, entonces, atravesada por voces sociales vinculadas a lo militar y a la feminidad.

Como indica Bonnin (2019b), la voz individual puede recurrir a voces sociales por distintos motivos, entre los cuales se encuentran obtener legitimidad. Esto es importante porque la legitimidad de la enunciadora, en nuestro ejemplo, se basa en la pertenencia a un grupo a partir de la diferenciación con respecto a otro grupo, que en este caso está compuesto por las aspirantes navales que también participan de la entrevista. Este análisis hace posible, entonces, el reconocimiento de identidades dominantes que entran en tensión con identidades marginadas, como es el caso de las mujeres que fueron soslayadas del discurso oficial argentino sobre la cuestión Malvinas.

\subsubsection{Ejemplo 2}

Veamos, ahora, una imagen que pertenece al corpus de la investigación doctoral de Caneva (2019) sobre las disputas discursivas por la despenalización y legalización del aborto en Argentina. En este ejemplo, que corresponde a una publicación de Facebook del año 2014, se podrá observar una imagen recurrente en el discurso de grupos anti-derecho al aborto, también autodefinidos como "Pro-vida". Teniendo en cuenta los componentes verbales (epígrafe, palabras que se montan sobre la imagen y el texto de la convocatoria) y no verbales (la imagen de la mujer, su postura corporal, los colores), en este posteo se puede observar que predomina una representación estereotipada de las mujeres que abortan, a quienes se ilustra como individuos que padecen consecuencias psicológicas y fisiológicas a causa de la interrupción del embarazo. Esta imagen es parte de una discursividad que durante los años previos a la sanción de la Interrupción Legal del Embarazo (ILE) en Argentina disputaba los sentidos dominantes sobre esta práctica y sobre el lugar social y político que corresponde a las mujeres en nuestra sociedad. Si bien el enunciado no da cuenta en forma directa de una interacción verbal entre personas concretas, al considerar los discursos como emergentes interaccionales podemos notar aquí un diálogo entre distintas voces sociales, particularmente de la salud mental y de la feminidad, así como una interacción entre este posteo específico y otros discursos previos y posibles en relación con el aborto. En particular, la imagen refuerza un sentido común que patologiza y condena moralmente la experiencia de las mujeres que abortan. Desde este punto vista, si el posteo analizado no es parte de una interacción social en el sentido goffmaniano, es decir, como la influencia que se ejerce sobre las acciones de un individuo que se encuentra físicamente presente, sí lo es en los términos discursivos propuestos. En este sentido, el ejemplo expuesto nos permite problematizar cómo los discursos producen/reproducen representaciones, imaginarios e identidades sociales que en muchos casos dan lugar a estigmas, en el sentido de Goffman. La caracterización negativa de la persona estigmatizada, producto de una tensión o discrepancia entre las identidades 
sociales virtual y real (Goffman 2019), se produce aquí discursivamente. ${ }^{7}$ El análisis, entonces, permite observar cómo, a partir de dispositivos como la publicación de Facebook se refuerzan normas, reglas, valores y rituales que inciden en las experiencias personales.

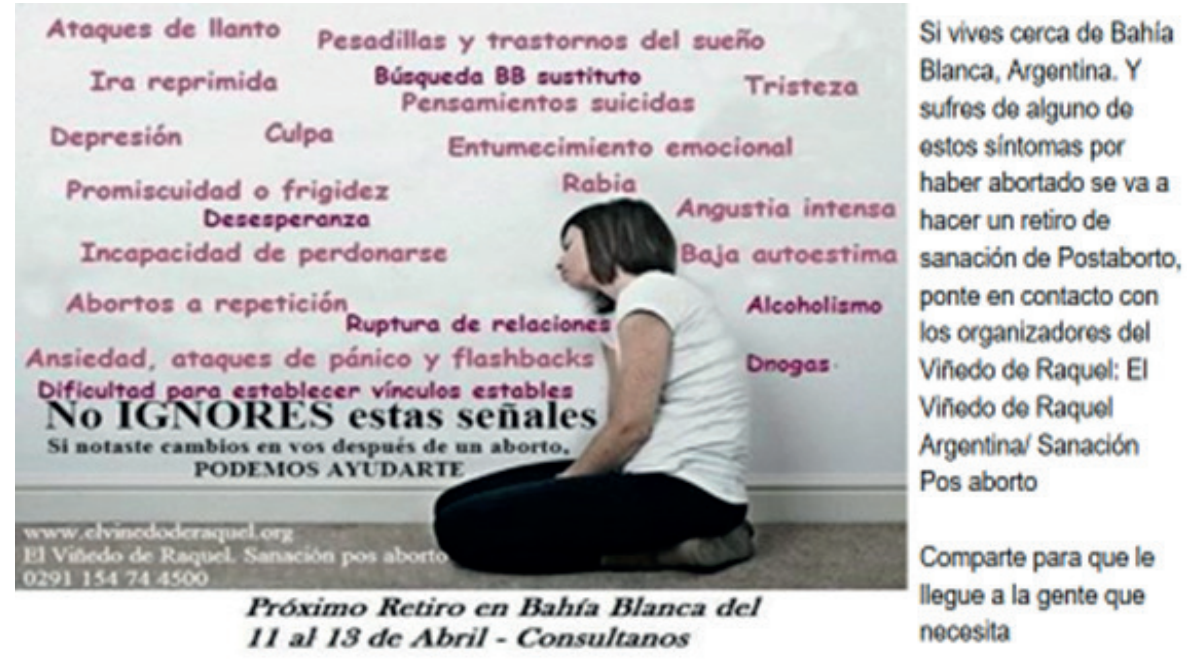

\section{Documento 9. Publicado el 22/03/2014 en https://www.facebook.com/Pro-Vida-Argentina:} $172789439455066 / 2$ fref=ts, Consultado el 21/11/2016

Imagen recuperada de: Caneva $(2019,152)$.

Resulta interesante, asimismo, recuperar el diálogo en el que esta imagen hiperritualizada sobre las patologías de las mujeres que abortan, reproducida en redes sociales y también en diversos medios de prensa gráfica, fue disputada durante aquellos años por el movimiento de mujeres y los feminismos, particularmente por La Campaña Nacional por el Derecho al aborto legal, seguro y gratuito. A partir del activismo digital, este colectivo propuso mostrar que la experiencia del aborto voluntario es común entre las mujeres y personas con capacidad gestante, por lo que no necesariamente se trata de una vivencia individual, solitaria y traumática ni de una experiencia sancionable social, moral ni punitivamente. Para desactivar los argumentos e imágenes hiperritualizadas de los grupos "Pro-vida", el discurso de La Campaña siguió diferentes estrategias retórico-argumentativas. Principalmente, su propósito al compartir imágenes de Facebook consistió en recuperar la voz social del feminismo mostrando a mujeres agrupadas a partir de la militancia y la lucha política en las calles. Esta identificación política colectiva, entendida también bajo la idea de "sororidad", generalmente se basaba en la denuncia de casos particulares de abusos a los derechos de mujeres que individualmente solicitaban abortos no punibles y se encontraban desatendidas y/o sancionadas. De esta manera, se propuso desafiar sistemáticamente un sentido común socialmente sedimentado según el cual las mujeres que abortan "están solas" y no cuentan con la defensa de la comunidad. La otra estrategia discursiva $-\mathrm{y}$, sobre todo, 
política- consistió en consolidar un "nosotras, las mujeres". Para ello, ya más cerca del debate parlamentario de 2018, se puso en primer plano la experiencia individual, con el fin de recoger diferentes narraciones en primera persona bajo la forma "yo aborté" y así demostrar que la experiencia está cargada de múltiples sentidos y significados compartidos, contrariamente al que la identifica con el drama y el sufrimiento. Así, las voces individuales fueron útiles para indexicalizar experiencias atravesadas por voces sociales en tensión: por un lado, aquella que asocia la mujer y lucha política y, por otro, la voz social de la feminidad conservadora. Se ve, entonces, cómo las voces individuales, que son parte de un discurso colectivo, cobran sentido a partir de las tensiones con voces sociales vinculadas a estereotipos de feminidad.

\section{Reflexiones finales}

A lo largo del artículo, hemos establecido un diálogo entre los estudios del discurso y la sociología con el fin de llevar adelante una línea de trabajo que, si bien tiene sus antecedentes, merece a nuestro entender mayor atención. Hemos partido de una problematización de los abordajes discursivos que desatienden las relaciones y tensiones entre lo individual y lo social y hemos subrayado desde un comienzo la necesidad de reconsiderar la agentividad de les hablantes en los enfoques discursivos preocupados por los mecanismos de dominación y hegemonía.

En primer lugar, revisamos tres aspectos del análisis del discurso que impulsaron nuestro diálogo interdisciplinario: la capacidad de agencia del sujeto, el tratamiento de corpora homogéneos y predominantemente escritos y la falta de flexibilidad metodológica. Seguidamente, hemos presentado la forma en que la sociología concibe las tensiones señaladas y nos hemos detenido en la microsociología de Goffman porque pensamos que el análisis de discursos debe considerar las interacciones de la vida cotidiana en sus dos dimensiones: la actuación individual y el hecho de que las prácticas ritualizadas están atravesadas por criterios de acción preestablecidos.

Por último, hemos esbozado una propuesta que consiste en articular una perspectiva discursiva y una sociológica, que valoran la agentividad del sujeto y nos permiten pensar en nuevas formas de tratar las investigaciones centradas en discursos. Así, no solo planteamos revisar nuestra posición de investigación en la producción de materiales con técnicas etnográficas, sino también recuperar la noción de voz como un concepto operativo para observar cómo las prácticas discursivas escenifican interacciones de distinta índole, entre hablantes y entre discursos. En otras palabras, nuestra propuesta consiste en articular discurso y teoría social, entendiendo la interacción en sentido amplio como diálogo tanto entre personas como entre voces. De esta forma, proponemos incorporar a la dimensión estructural el eje individual que tiende a ser soslayado en los enfoques discursivos. Los ejemplos que hemos proporcionado de nuestras investigaciones pretenden ilustrar algunas de las preguntas que planteamos y dos posibles formas de abordar los fenómenos sociales desde una mirada discursiva y, 
como tal, interdisciplinaria. Surge aquí, sin embargo, la pregunta por los alcances de una perspectiva combinada como la que proponemos. Si bien en esta ocasión tomamos dos análisis específicos, pensamos que, en tanto los discursos son eminentemente dialógicos, el abordaje propuesto se puede extender a distintos tipos de corpora. Queda pendiente una profundización sobre esta cuestión.

Finalmente, resta preguntarnos cuán permeables son las fronteras analíticas que tensionan lo individual y lo social, y si en realidad el asunto de fondo radica en el tipo de problemas que les investigadores queremos iluminar o en la mirada epistemológica con que abordamos nuestras investigaciones. Porque, si la sociedad se construye a partir de las interacciones entre agentes en situaciones concretas, asimismo debemos considerar que tales interacciones están orientadas por acervos culturales, creencias, conocimientos, habilidades y expectativas mutuas. Si la socialización se vincula con la introyección de normas, valores y reglas que permiten ocupar papeles o roles, un análisis interdisciplinario que incorpore el abordaje de discursos en los que se construye la experiencia individual puede ser un aporte para desentrañar cómo se producen tales condicionamientos y cómo se modifican. 


\section{Q Bibliografía}

»Alexander, Jeffrey. 2000. Las teorías sociológicas desde la Segunda Guerra Mundial. Barcelona: Gedisa.

" Amossy, Ruth. 2018. La presentación de sí. Ethos e identidad verbal. Buenos Aires: Prometeo. (Primera edición en francés en 2010).

" Amossy, Ruth y Herschberg Pierrot, Anne. 2001. Estereotipos y clichés. Buenos Aires: Eudeba. (Primera edición en francés en 1997).

» Arnoux, Elvira. 2019. "El Análisis del Discurso como campo académico y práctica interpretativa”. En Métodos de Análisis del Discurso. Perspectivas argentinas, coordinado por Oscar Iván Londoño Zapata y Giohanny Olave Arias, 18-39. Bogotá: Ediciones de la U.

»Arnoux, Elvira. 2006. Introducción al Análisis del Discurso. Modos de abordar materiales de archivo. Buenos Aires: Santiago Arcos.

» Arfuch, Leonor. 2002. El espacio biográfico. Dilemas de la subjetividad contemporánea. Buenos Aires: Fondo de Cultura Económica.

"Atkinson, Maxwell y Heritage, John, eds. 1984. Structures of Social Action: Studies in Conversation Analysis. Cambridge: Cambridge University Press.

》Baxter, Judith. 2003. Positioning gender in discourse. A feminist methodology. Nueva York: Pallgrave-Macmillan.

» Blommaert, Jan. 2005. Discourse. A Critical Introduction. Cambridge: Cambridge University Press.

» Bolívar, Adriana. 2018. Political Discourse as Dialogue: A Latin American Perspective. London: Routledge.

"Bolívar, Adriana. 2010. "A change in focus: from texts in contexts to people in events". Journal of Multicultural Discourses, 5(3): 213-225.

" Bonnin, Juan Eduardo. 2019a. Discourse and mental health. Voice, inequality and resistance in medical settings. New York: Routledge.

》Bonnin, Juan Eduardo. 2019b. (Des)afiliación y (des)alineamiento: procedimientos interaccionales para la construcción de voz. Pragmática Sociocultural, 7(2): 231-252.

"Bucholtz, Mary y Kira Hall. 2005. Identity and interaction: a sociocultural linguistic approach. Discourse Studies, 7: 585-614.

" Caneva, Hernán A. 2019. "Disputas por el aborto en Argentina: Análisis crítico de discursos en dos organizaciones (2014-2016)". Tesis de doctorado, Universidad Nacional de La Plata. Facultad de Humanidades y Ciencias de la Educación. Recuperado de http://sedici.unlp.edu.ar/handle/10915/77915.

»Collins, Randall. 1996. Cuatro tradiciones sociológicas. México: Universidad Autónoma Metropolitana.

》Durkheim, Émile. 1982. Las formas elementales de la vida religiosa (Vol. 38). Buenos Aires: Akal.

" Fairclough, Norman. 2013. Critical Discourse Analysis: The critical study of language. London and New York: Routledge.

"Fairclough, Norman. 2003. Analysing discourse. Textual analysis for social research. Londres: Routledge. 
» Fairclough, Norman. 1992. Discourse and Social Change. Cambridge: Polity.

» Fairclough, Norman y Ruth Wodak. 2000. “Análisis crítico del discurso”. En El discurso como interacción social, compilado por Teun van Dijk, 367- 404. Barcelona: Gedisa.

» Flax, Rocío. 2021. “Análisis Crítico del Discurso y materialismo histórico, ¿una posible reconciliación?”. Conferencia presentada en I Sesión sobre Lingüística Materialista, organizado por Revista Refracción e Instituto de Lingüística Materialista de la Universidad de Murcia. Fecha: 17 de febrero de 2021. https://www.youtube.com/watch?v=4H1ggxKe848

» Foucault, Michel. 1970. Arqueología del saber. México: Siglo XXI. (Primera edición en francés en 1969).

» Giddens, Anthony y Jonathan Turner, eds. 1990. La Teoría Social Hoy. Madrid: Alianza.

" Goffman, Erving. 2019. Estigma. La identidad deteriorada. Buenos Aires: Amorrortu. (Primera edición en inglés en 1963).

» Goffman, Erving. 1997. La presentación de la persona en la vida cotidiana. Buenos Aires. Amorrortu. (Primera edición en inglés en 1959).

» Goffman, Erving. 1991. La ritualización de la femineidad. Los momentos y sus hombres. Barcelona: Paidós.

» Haraway, Donna. 1995. Ciencia, Cyborgs y Mujeres. Madrid: Cátedra.

» Joseph, Isaac. 1999. Erving Gofman y la micro-sociología. Barcelona: Gedisa.

» Labov, William. 1972. Sociolinguistic Patterns (Conduct and Communication). Philadelphia: University of Pennsylvania Press.

» Lazar, Michelle, ed. 2005. Feminist Critical Discourse Analysis. Gender, power and ideology in discourse. Nueva York: Palgrave Macmillan.

» Lerner, Gene H., ed. 2004. Conversation Analysis: studies from the first generation. Philadelphia: John Benjamins Publishing.

» Maingueneau, Dominique. 1999. “Peut-on assigner des limites à l'analyse du discours?”. Modèles linguistiques, XX, 2: 61-70.

» Martin, James. 2004. “Positive Discourse Analysis Solidarity and Change”. Revista Canaria de Estudios Ingleses, 49: 179-202.

» Martínez Romagosa, Maite y Flax, Rocío. 2020. “Desalienar el ACD: Una revisión de la noción de ideología para devolver la crítica marxista al Análisis Crítico del Discurso". Pensamiento al margen. Revista Digital de Ideas Políticas, 12: 54-66.

»Pêcheux, Michel. 1975. Les vérités de La Palice: Linguistique, sémantique, philosophie. París: Maspero.

»Pêcheux, Michel. 1984. “Sur les contextes épistémologiques de l’AD”. Mots, 9.

» Raiter, Alejandro. 2014. "Crítica del uso del lenguaje o crítica de algunos usos”. Kaf, 3: 22-29.

"Salgado Andrade, E. 2019. Los estudios del discurso en las ciencias sociales. México: Universidad Nacional Autónoma de México.

» Salerno, Paula. 2019. "Islas Malvinas: discursos presidenciales y su repercusión en la prensa (2004-2015)". Tesis de doctorado, Universidad de Buenos Aires, Facultad de Filosofía y Letras.

»Salerno, Paula. 2021a. "Relaciones entre los estudios del discurso y la memoria colectiva”. II Sesión de Lingüística Materialista. Organizada por Revista Refracción e Instituto 
de Lingüística Materialista (INLIMA) de la Universidad de Murcia. Conferencia virtual. 16 de marzo de 2021. https://www.youtube.com/watch?v=f-9oWZx4SGE.

"Salerno, Paula. 2021b. "Mujeres en la guerra de Malvinas: discurso, memoria e identidades", YouTube El derecho a la palabra, Proyecto UBACyT "El derecho a la palabra: perspectiva glotopolítica de las desigualdades/diferencias 3". Recuperado de https:// www.youtube.com/watch?v=RkxOjIT-QEM\&t=371s.

"Shi-Xu 2015. “Cultural discourse studies". En International Encyclopedia of Language and Social Inter-Action, editado por Karen Tracy, Cornelia llie y Todd Sandel, 1-9. Boston, MA: Wiley-Blackwell.

»Tusón Valls, Amparo. 1997. Análisis de la conversación. Ariel: Planeta.

"Unamuno, Virginia y Juan E. Bonnin. 2018. “'We work as bilinguals': Socioeconomic changes and language policy for indigenous languages in El Impenetrable (Chaco, Argentina)". En The Oxford handbook of language policy and planning, editado por James W. Tollefson y Miguel Pérez-Milans. Oxford: Oxford University Press.

"Wodak, Ruth y Michael Meyer. 2001. Methods of critical discourse studies. London: Sage.

"Wodak, Ruth. 1996. Disorders of discourse. Londres: Longman.

"Wodak, Ruth. 1995. “Critical linguistics and critical discourse analysis”, en Handbook of Pragmatics: Manual, editado por Verschueren, J. et al., 204-210. Amsterdam: John Benjamins.

"Zima, Pierre. 2005. "Le concept de théorie en sciences humaines. La théorie comme discours et sociolecte". En Sciences du texte et analyse de discours, coordinado por JeanMichel Adam et Ute Heidmann, 21-36. Ginebra: Slatkine Érudition. 